and will target areas in which China has a chance to dominate. One team, for which Poo has already selected 40 researchers from 11 different CAS institutes, specializes in brain science - one goal is to produce a transgenic monkey model that could be useful for neurodegenerative-disease research.

Tandong Yao, director of the Institute of Tibetan Plateau Research in Beijing will head another centre focused on the seismically active plateau: his team wants to probe how the crust underneath deformed over time. Other centres will focus on particle physics, thorium-based molten-salt reactors, and quantum information. The plan is to take the count up to 20 centres by 2020 .

A second category will target areas with underdeveloped commercial potential, including microsatellites, marine information technology and drug development. A third category will establish collaborations around large-scale facilities: a synchrotron and a protein-science centre, for example, both in Shanghai, will be linked to make it easier to carry out high-precision protein studies and support academic and industry researchers, including some from abroad.

The fourth category, still in its design phase, will be devoted to initiatives that assist local development and sustainability. Its first will probably focus on work by the Institute of Mountain Hazards and Environment in Chengdu, which could help communities to prepare for natural disasters such as landslides.

But not everyone agrees that the changes tackle the key problems at the CAS. One Chinese university scientist, who is familiar with the reforms and did not want to be identified, says that the source of the problems is that the CAS hires too many young scientists who then go through little or no review, and essentially receive tenure without having to prove themselves. Bai counters that the opportunities offered by his initiatives will "encourage the underperformers to be better". He says that he has steered away from a US-style system in which underperformers can be fired: "It is a reform with Chinese characteristics."

Cong Cao, a science-policy specialist at the University of Nottingham, UK, says that the CAS is too big and unwieldy. "There's no organization in the world with so many functions," he says. He says that universities and individual research institutes, which are increasingly competing with the CAS for leading scientists, can offer a better management environment for scientists. "There probably is no reason for the CAS in China right now."

But Bai uses the same trait to justify the academy's existence: he argues that it allows the CAS to make wide contributions to China's development. "You have to understand the history," he says.

\title{
Global Ebola response kicks into gear at last
}

\section{US and UN mobilizations are welcome but overdue.}

\section{BY DECLAN BUTLER}

$\mathrm{T}$ The international community is responding to the Ebola outbreak - at long last. On 18 September, the United Nations Security Council adopted a resolution declaring the outbreak a "threat to international peace and security"; two days before, the United States had said that it will send 3,000 military personnel to West Africa and spend US\$750 million to support civilian efforts. Both moves are unprecedented for a disease outbreak and just what is needed, say experts. But there are fears that quelling the outbreak now will be more difficult than if it had been tackled earlier.

The Ebola outbreak was first detected in March, but only the humanitarian group Médecins Sans Frontières (MSF, or Doctors Without Borders) has so far deployed substantial relief in the affected region, which centres on Liberia, Sierra Leone and Guinea (for more, see nature.com/ebola). MSF has repeatedly demanded that the international community launch a major effort to tackle the outbreak.

The UN resolution calls on member states to respond urgently. As it was passed, UN secretary-general Ban Ki-moon launched the United Nations Mission for Ebola Emergency Response to deploy resources from UN agencies in coordination with efforts from member nations and donors. The mission's remit includes "stopping the outbreak, treating the infected, ensuring essential services, preserving stability and preventing further outbreaks," said Ban.

The United States plans to establish military-run command and control headquarters in Liberia and build 17 treatment centres of 100 beds each in the affected region. It hopes to recruit medical staff to run them, and train up to 500 health-care workers a week.

The public-health community tends to view military involvement "with suspicion and mistrust", says Adam Kamradt-Scott, a health-policy researcher at the University of Sydney in Australia. But he welcomes the US plan: "Military forces have unique skill sets that can assist civilian authorities." If the operation does help to counter Ebola, he adds, it could set a new precedent for responding to disease outbreaks of international concern.

Training forces in outbreak response will take time, warns Daniel Bausch, who studies infectious diseases at Tulane University in New Orleans, Louisiana, and is caring for people with Ebola in Sierra Leone. He adds that the situation is too dire for the United States alone to solve, and that other nations must step in, something that the UN resolution should catalyse. It was passed by unanimous vote and had a high number of member-state sponsors.

Jean-Clément Cabrol, director of operations for MSF in Geneva, Switzerland, says that both efforts are welcome, but that the situation has worsened in the past few weeks, so speed is key. Treatment centres in the three countries most affected are completely overwhelmed

"Military
forces have
unique skill
sets that can
assist civilian
authorities."
(see page 474). This is fuelling the spread of the disease, because centres are forced to send away infected people, who then contaminate others.

Conventional publichealth measures are no longer working, says Bausch. It has become next to impossible to detect and isolate those infected, and to monitor all the people they have been in contact with. He recommends focusing surveillance on areas next to affected zones to prevent further geographical spread of Ebola. He adds that international efforts will be effective only if they include training for health-care staff, for example in biosafety. Money and supplies are welcome, but by themselves, they are not enough. @ SEE EDITORIALP.459

\section{MORE ONLINE TOP NEWS}

- Population boom to last all century go.nature.com/xnsblj

- Male astronomers get bigger share of Hubble go.nature.com/v9e807

\section{IMAGE OF THE WEEK}

This map measures dust in the southern Galactic hemisphere. It suggests that

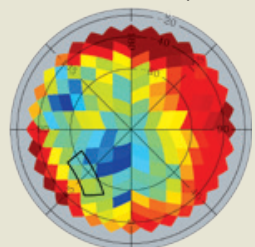
a signal of gravitational waves from the Big Bang previously observed in the black rectangle

could have been spurious. go.nature.com/ifalmw 